\title{
Shortfin mako sharks speeding to the brink
}

Overfishing has reduced abundances of sharks worldwide, with functional extinction of some species in former habitat strongholds $(1,2)$. The world's fastest shark, the shortfin mako (Isurus oxyrinchus), is globally endangered (3) but remains overfished in the North Atlantic and in high demand commercially for its meat and fins $(3,4)$. Despite these threats to the species, influential fishing nations continue to block policies that would follow scientific recommendations for rebuilding shortfin mako populations by reducing catches in areas beyond national jurisdictions (the "High Seas"). At the November 2020 Meeting of the International Commission for the Conservation of Atlantic Tunas (ICCAT), the European Union and United States ignored ICCAT's own scientific advice and blocked a catch retention ban for North Atlantic mako proposed by Canada, Senegal, the United Kingdom, Chinese Taipei, and Gabon (5). Blocking a retention ban delays hopes of ending overfishing. The latest shortfin mako stock assessment estimates that North Atlantic stock recovery can be achieved by 2070 with a $60 \%$ chance if the total allowable catch-including dead discards-is less than 300 tons (6). However, current catches-excluding discards-are already more than 6 times this number (4). Even with zero retention, reducing capture and post-release mortalities will be necessary. An annual mortality of 1100 tons, already greatly exceeded in 2019 (4), gives only an $8 \%$ chance of rebuilding by 2070 (6). In 2019, shortfin makos were included in Appendix II of the Convention on International Trade in Endangered Species of Wild Fauna and Flora, regulating trade for this species (7), but additional measures are needed. In addition to reversing course to support a retention ban, the European Union and United States should show appropriate leadership in shark conservation by decreasing fishing effort and implementing area-based management tools (such as marine reserves) (8) that are capable of protecting key shark hotspots (9). Achieving these as part of a new United Nations High Seas treaty (10) may fast become the last management refuge for rebuilding oceanic shark populations. 
David W. Sims ${ }^{1,2^{*}}$, Gonzalo Mucientes ${ }^{3,4}$, Nuno Queiroz ${ }^{1,4}$

${ }^{1}$ Marine Biological Association of the UK, Plymouth

PL1 2PB, UK.

${ }^{2}$ University of Southampton,Southampton SO14 3ZH, UK.

${ }^{3}$ Instituto de Investigaciones Marinas-Spanish Research

Council (IIM-CSIC), 36208 Vigo, Spain.

${ }^{4}$ Centro de Investigação em Biodiversidade e Recursos Genéticos/Rede de Investigação em

Biodiversidade e Biologia Evolutiva, Universidade do Porto, 4485-661 Vairão, Portugal.

*Corresponding author. Email: dws@mba.ac.uk

\section{REFERENCES AND NOTES}

1. D. J. McCauley et al., Science 347, 1255641 (2015).

2. M. A. MacNeil et al., Nature 583, 801 (2019).

3. C. L. Rigby et al., Isurus oxyrinchus (The IUCN Red List of Threatened Species, 2019).

4. International Commission for the Conservation of Atlantic Tunas, "2020 Standing Committee on Research and Statistics (SCRS) advice to the commission" (Madrid, Spain, 2020).

5. ICCAT, "2020 Commission Documents: Summary Report by the Chair of Panel 4" (Madrid, Spain, 2020).

6. ICCAT, "Report of the 2019 Shortfin Mako Shark Stock Assessment Update Meeting" (Madrid, Spain, 2019); www.iccat.int/Documents/SCRS/DetRep/SMA_SA_ENG.pdf

7. Convention on International Trade in Endangered Species of Wild Fauna and Flora, in Resolution Conf. 12.6 (Rev. CoP18) (2019); https://cites.org/sites/default/files/document/ERes-12-06-R18.pdf.

8. G. Ortuño Crespo et al., Mar. Pol.122, 104102 (2020).

9. N. Queiroz et al., Nature 572, 461 (2019).

10. G. Ortuño Crespo et al., Nat. Ecol. Evol. 3, 1273 (2019). 